\title{
Assessment of Serum Levels of Magnesium and Manganese among Pregnant Women at Central Hospital, Agbor, South-South Nigeria
}

\section{${ }^{*}$ HUMPHREY; B. OSADOLOR ${ }^{2}$ CHRISTABEL C.OMOGIADE}

\author{
School of Basic Medical Science, University of Benin, Benin City, Nigeria \\ Dept. of Medical Laboratory Science, University of Benin, Benin City, Nigeria \\ Humphrey B. Osadolor, PhD, School of Basic Medical Sciences, \\ University of Benin, Benin City, Nigeria. \\ Correspondence: E-mail: humphrey.osadolor@uniben.edu \\ Phone: +2347060813792
}

\begin{abstract}
Pregnant women in developing countries have been reported to consume diets with low density of minerals and essential trace elements. Therefore, this study aims to assess the serum levels of magnesium and manganese and its trimester correlates among pregnant women in Ika community of Delta state, Nigeria. An analytical cross-sectional study was conducted to assess the serum levels of magnesium and manganese among 64 apparently healthy pregnant and age matched 25 healthy non-pregnant women attending antenatal clinic at obstetrics and gynaecology unit of central hospital Agbor. The mean serum levels of manganese increased with increase in gestational age while hypomagnesaemia $12.24 \mathrm{ug} / \mathrm{dl}$ was observed in 60 (93.8\%) of the pregnant women with a larger preponderance in the second trimester There was significant difference between the serum level of manganese in pregnant women compared to non-pregnant women $(\mathrm{p}<0.001)$. There were no statistical significance between the serum levels of these trace elements and occupation, nature of dietary intake, age of participants and trimester of pregnancy.We observed an increase in the mean serum levels of manganese with trimester progression while a high prevalence rate $(93.8 \%)$ of magnesium deficiency among pregnant women was noted in this study. Maximal awareness (advocacy) should therefore be given to pregnant women on the need for adequate dietary intake and supplementation to avoid the complications associated with deficiency of this nutrient. (C) JASEM
\end{abstract}

http://dx.doi.org/10.4314/jasem.v19i4.6

KEYWORDS: Magnesium, Manganese, Pregnant, Women, Agbor, Nigeria

\section{INTRODUCTION}

Micronutrient deficiency in women of reproductive age is recognized as a major public health problem in many developing countries with attendant morbidities (Ramakrishman,2002). Micronutrient (essential trace elements) are those elements that are required in minute quantities by an organism to maintain normal complex metabolism (e.g. metalloproteins) which are required in enzymatic activities and can play structural role in connective tissues or cell membranes (Goldstein, 1990).

Manganese (Mn) is an essential dietary mineral and a component of the metalloenzymes such as superoxide dismutase, arginase and pyruvate carboxylase, which plays an important role in a number of physiologic processes such as amino acid, lipid and carbohydrate metabolism (Institute of Medicine,2001, Nicoloff et al 2004).

Magnesium $(\mathrm{Mg})$ is also a trace element which is ingested with food or water and it is needed to stay healthy as is an essential cofactor for multiple enzymes involved in glucose metabolism and it has been postulated to play a role in glucose homeostasis, insulin action and in the development of type 2 diabetes mellitus (Larson \& Wolk,2007).
An imbalance in the levels of these trace elements is therefore worrisome, more so in a pregnant woman. Nutritional deficiencies are common during pregnancy and pregnant women in developing countries have been reported to consume diets that are low in minerals and vitamins (Keen et al, 1998 ,Adam et al,2001,). There is a growing fear that compromised magnesium nutritional status may be involved in several disorders that can occur during pregnancy. These include hypertension, vasospasm, coagulation defects,type 2 diabetes mellitus,premature delivery, intrauterine growth retardation and muscle cramping. Deficiencies of trace elements such as zinc, copper, selenium and magnesium have been implicated in various reproductive events like infertility, spontaneous abortions, congenital anomalies, pre-eclampsia, placental abruption, premature rupture of membranes, still births and low birth weight (Hofmeyr et al, 2007). Magnesium deficiency can paradoxically increase the risk of, or protect against oncogenesis (Cortes and Moses, 2007). It has been proposed that $\mathrm{Mg}$ is central in the cell cycle, and that its deficiency is an important conditioner in precancerous cell transformation. Also, at high levels, magnesium can cause damage to the brain, liver, kidneys, and the developing foetus (Smith et al, 2007). 
Demonstration of Mn deficiency syndrome has been less clear although it has been associated with several chronic diseases like osteoporosis, epilepsy and diabetes mellitus (Nicoloff et al,2004). On the contrary, prolonged industrial exposure causes increases in serum manganese to greater than $5.4 \mu \mathrm{g} / \mathrm{L}$ $(>30 \mathrm{nmol} / \mathrm{L})$ which is an indices of manganese retention that typically manifest with neurological symptoms in pregnant women (Burtis, 2008). Although it is increasingly acknowledged that societal factors play a significant role in micronutrient status and pregnancy outcomes (Aydemir et al,2003, Chandra,2008), studies on impacts of socioeconomic status on pregnancy outcomes have produced conflicting reports (Tuntiseranee et al,1999).

Major researches have also shown that serum magnesium and manganese levels are lower in pregnant women especially in rural and developing countries which may be due to poverty, lack of knowledge about adequate prenatal nutrition or other factors such as water hardness, mal absorption associated with disease or inadequate intakes and dietary taboos associated with pregnancy. More so with westernization of our diet, it has become of great concern to the African man because many of such refined foods contain less of these trace elements because of the micronutrient status of soils and plants following agro farming compared to fresh vegetables and fruits which we get from our subsistence farming hence resulting in deficiencies with adverse consequences for both mother and newborn infants (Gittelsohn et al,1997).

In the light of this, it is therefore justifiable to find out what the levels of these trace elements are among Ika community residing in a semi-urban area of Nigeria, because an imbalance in the levels of these trace elements is worrisome, more so in a pregnant woman. We hypothesise that changes in the serum levels of trace elements among pregnant women may have contribution from the socioeconomic status.

\section{MATERIALS AND METHODS}

Study Design: This was an analytical cross sectional study designed to assess the serum levels of magnesium and manganese among pregnant women in Ika community, Delta state, south-south Nigeria.

Study Area And Population: Ika constitute a major ethnic group in the whole area of delta north senatorial district (Anioma) with Agbor being the local government headquarters. Agbor is a semiurban community in Ika south local government area of delta state. It is located at latitude $6.26 \mathrm{~N}$ and longitude $6.19 \mathrm{E}$, with population of over 67,616 people. The main occupation of the dwellers is subsistence farming; mainly yam and cassava with some animal husbandry. Other professionals such as civil servants, traders, and artisans also constitute their work force. Majority of those recruited had low level of education (primary and a few with secondary education). The study population involved pregnant women attending the antenatal clinic of central hospital Agbor and age matched non-pregnant women.

Study Duration: The study was carried out within a three month period (January 2010 to March, 2010) in which a total of 89 patients were recruited. Sample were collected twice weekly from the Wednesday and Friday clinic of the obstetrics and gynaecology unit.

Sample Size Estimation: Sample size was determined by using this formula (n) $=\underline{Z}_{\alpha}{ }^{2} S^{2}$ $\mathrm{d}^{2}$ Using the standard deviation of magnesium of 0.20 (Akinloye et al, 2010) and a degree of attrition of $4 \%$, a minimum sample size of 96 was calculated. However, 96 subjects were actually recruited,but only 89 of them gave their consent,so $n=89$ (64 pregnant and 25 non pregnant women). Ethical consideration was sought from the hospital and informed consent obtained from participants. The study was conducted according to the revised version of the declaration of Helsinki (Tatsuo,2009)

Inclusion Criteria: Healthy non-lactating, nonsmoking and non-alcoholic pregnant and nonpregnant women (control) were included in the study.

Exclusion Criteria: Lactating mothers, smoking and alcoholic individuals were excluded from this study. Women with acute and chronic illnesses such as hypertension or taking any other medications that could potentially affect levels of trace elements were also excluded.

Sample Collection: Five millilitre of venous blood sample was collected from each of the subjects with sterile disposable needles and syringes. This was dispensed into a clean dry plain container while avoiding haemolysis. Sample was placed on the bench and allowed to stand for at least 1 hour before centrifuging. The serum was then transferred to vials and stored at $-20^{\circ} \mathrm{C}$ until batch analysis.

Biochemical Analysis And Principle: Serum magnesium and manganese were determined by flame atomic absorption spectrophotometry using a direct method as described by Kaneko (1999).

The atoms of the element, when aspirated into the atomic absorption spectrophotometer (AAS), vaporized and absorbed light of the same wavelength as that emitted by the element when in the excited state. The amount of light absorbed in the flame is proportional to the concentration of the element in the sample. 
Procedure: Spectrophotometric measurement of serum concentrations of magnesium and manganese were performed on a Beck 200 atomic absorption spectrophotometer (AAS). The samples were thawed and 1:20 dilution made with $0.1 \mathrm{~N} \mathrm{HCl}$ then aspirated directly into AAS for analysis. Working standard solutions were prepared by diluting the stock standard with $0.1 \mathrm{~N} \mathrm{HCl}$ and the required part per million (ppm) used for the standardization of the corresponding trace elements.

The reference values used here were similar to those previously documented in the literature.

Serum level of Magnesium $=1.6-2.6 \mathrm{mg} / \mathrm{dl}(16-$ 26mg/l) (Physicians, 2005). Reference range for serum manganese $=5-13 \mathrm{mcg} / \mathrm{L}(9-24 \mathrm{nmol} / \mathrm{L})$ (Burtis et al, 2008).

Statistical Analysis: Data were collated, inputted into a computer and statistical analysis performed using SPSS version 22 software. Data obtained from this study were expressed as mean and standard deviation. The differences between groups were compared using the independent sample student t-test and one-way analysis of variance (ANOVA). Pearson correlation coefficient was used to measure the level of association between serum levels of magnesium and manganese. $\mathrm{P}<0.05$ was used as level of significance at a $95 \%$ confidence interval for all analysis. Results were represented in tables and bar charts.

\section{RESULTS AND DISCUSSION}

Ninety six patients were recruited for the study however, only 89 subjects including 64 healthy pregnant women aged 19-49 years and 25 age matched control subjects (healthy non-pregnant females) consented to participate in the survey; giving a response rate of $92.7 \%$.

Table 1: Socio-demographic characteristics of the pregnant women $\mathrm{N}=64(100 \%)$

\begin{tabular}{lcc}
\hline Variable & frequency & $(\%)$ \\
Age & & \\
$18-33$ & 54 & 84.4 \\
$34-49$ & 10 & 15.6 \\
Occupation & & \\
Farming & 15 & 23.4 \\
Civil servant & 15 & 23.4 \\
Self-employed & 22 & 34.4 \\
Home marker & 12 & 18.8 \\
\hline
\end{tabular}

Above socio-demographic factors have no significant association with serum level of trace element $(\mathrm{P}>$ $0.05)$

We observed a rise in serum levels of magnesium with increase in gestational age while serum level of manganese decreased with increasing gestational age. However, the observed difference was not significant. There was a statistically significant difference in the serum level of magnesium between first and third trimester pregnancy after subjecting it to a post Hoc test. $\mathrm{P}=0.02$.

This is a very weak positive correlation between the serum levels of the trace elements among pregnant women. This observed association is not statistically significant.

We also correlated age against serum levels of trace elements and found a very weak positive correlation with $\mathrm{Mg}$ ( $\mathrm{c}=0.121, \mathrm{p}=0.341)$ and a very weak negative correlation with $\mathrm{Mn}(\mathrm{c}=-0.028, \mathrm{p}=0.826)$. Both were not statistically significant.

Pregnancy is a hyper metabolic state and as such the demand for both energy and nutrients is increased during pregnancy and thereby making these women vulnerable to nutritional deficiencies because of the increased metabolic demands imposed by the growing foetus (Mistry et al 2011, Emokpae et $a l, 2015)$.

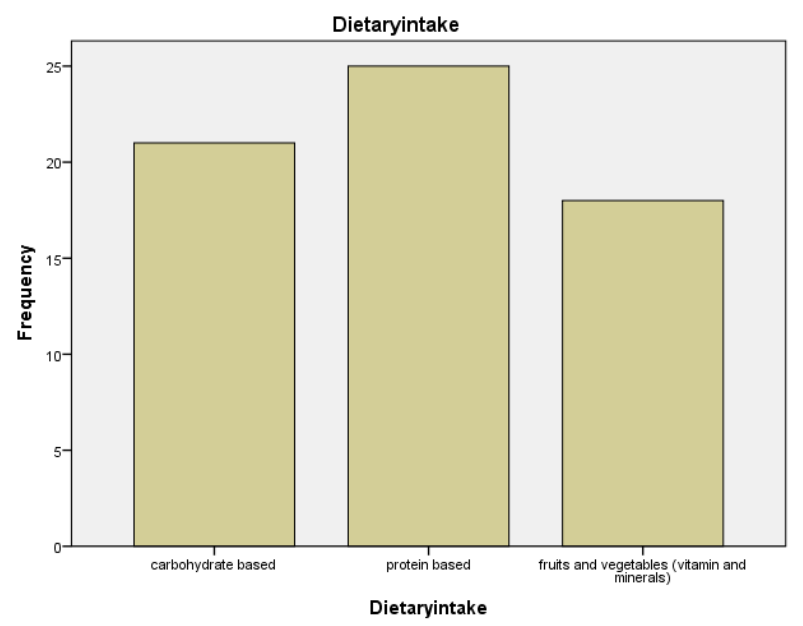

Fig.I: Dietary intake by pregnant women

Two essential mineral elements were studied to estimate their serum levels for the purpose of establishing the baseline status in pregnancy among Ika women of Delta state, Nigeria. It is hoped that the knowledge of their mineral status will be helpful in guarding against mineral deficiency or overload in the course of management, so as to ensure a better pregnancy course. We found an increased level of serum manganese with increase in gestational age however hypomagnesaemia was recorded in 60 pregnant women (93.8\%) involving all the three trimesters but more in second trimester (96.2\%). A similar study done in Benin City, Nigeria also recorded hypomagnesaemia with negative correlation with gestational age (Krebs and Briggs, 1923).

The first reports of blood magnesium levels during pregnancy was done in 1923 by Krebs and Briggs who reported a range of 1.7-2.2 $\mathrm{mEq} /$ liter among 17 women in their 8th to 40th weeks of pregnancy. In our study, we found a range of $0.84-1.86 \mathrm{mg} / \mathrm{dL}$ for 
the pregnant women and $1.06-1.69 \mathrm{mg} / \mathrm{dL}$ for the control group. Both values were far lower than the reference values.

Celli (1965) did a study which compared the serum levels of 40 pregnant women at different stages of pregnancy with those of non-pregnant women and found that the average value $2.0 \mathrm{mEq} / \mathrm{liter}$ at the outset (which equalled the control average) fell to an average of 1.7 by the end of pregnancy. This was similar to our finding of equal mean of serum magnesium during first trimester with the control $(1.31 \mathrm{mg} / \mathrm{dL})$ which dropped to $1.16 \mathrm{mg} / \mathrm{dL}$ in the third trimester.

Majority of pregnant women who ate protein based diet where in the second trimester while those that ate more of vegetables and fruits where in the second $(38.9 \%)$ and third trimester $(33.3 \%)$ respectively.

Table 2: Mean values of trace elements, pregnant women versus control. Microelement Test Subjects (no) Means Std Error Std Deviation P-value

\begin{tabular}{lllllcl}
\hline & Pregnant & 64 & 12.24 & 0.24 & 1.94 & $\mathrm{P}>0.05$ \\
\hline $\mathrm{Mg}(\mathrm{mg} / \mathrm{mL})$ & Control & 25 & 13.78 & 0.36 & 1.78 & \\
\hline & Pregnant & 64 & 23.15 & 0.93 & 7.40 & $\mathrm{P}<0.05$ \\
$\mathrm{Mn}(\mu \mathrm{g} / \mathrm{dl})$ & Control & 25 & 39.26 & 1.71 & 8.56 & \\
\hline
\end{tabular}

Serum magnesium was lower in pregnant subjects compared with non-pregnant controls $\mathrm{P}>0.05$ while serum manganese in pregnant subjects significantly lower when compared with non-pregnant women $\mathrm{P}<0.05$.

Lower serum levels of magnesium of $1.9 \mathrm{mEq} /$ litre measured during the third trimester of pregnancy compared to a level of $2.2 \mathrm{mEq} /$ litre in healthy non-pregnant women has been reported by Celli Acella The author suggests that these differences, taking into account the increasing demands of the rapidly growing foetus, may indicate an occult magnesium deficiency. We had about $94 \%$ of our pregnant women who were hypomagnesaemic at different levels of gestation but with a larger preponderance in the second trimester. In comparism with the pregnant women an apparently higher level of serum magnesium except in the first trimester where they were same was observed the control group. Similar studies have acknowledged the development of hypomagnesaemia in pregnancy (Mahran \& Hanna,1968). DeJorge et al affirmed that this results from correction of the dilution of plasma that occurs during pregnancy in their study of 139 pregnant women, and they concluded that the hypomagnesaemia is real only during the first half of pregnancy and during the last month . Development of hypomagnesaemia in early pregnancy could be explained by the development of hyper emesis that can lead to loss of minerals, including magnesium and even reduce intake (Magum et al, 1985). We however did not elicit such from our patients

Table 3: Mean values of trace elements among pregnant women versus age of respondents, occupation and dietary intake.

\begin{tabular}{lccc}
\hline Serum Mg (standard deviation) & \multicolumn{3}{c}{ Serum Mn (standard deviation) } \\
\hline Age & 12.24 & $(2.00)$ & $23.64(7.58)$ \\
$18-33$ & 12.22 & $(1.67)$ & $20.47(6.01)$ \\
$34-49$ & & & \\
Occupation & 12.15 & $(1.24)$ & $22.29(7.25)$ \\
Farming & 11.66 & $(1.57)$ & $21.43(6.48)$ \\
Civil servants & 12.31 & $(2.07)$ & $23.79(7.86)$ \\
Self-employed & $12.93(2.68)$ & $25.18(8.07)$ \\
Home maker & & & \\
Dietary intake & $12.58(2.04)$ & $23.97(6.98)$ \\
Carbohydrate & $12.03(1.99)$ & $22.79(7.18)$ \\
Protein based diet & $12.12(1.78)$ & $22.69(8.46)$ \\
Vegetables \& fruits &
\end{tabular}

The mean serum levels of Magnesium and Manganese declined with increase in age. This observed difference is however not statistically significant. [ $\mathrm{t}=0.028 ; \mathrm{P}=0.978 ; \mathrm{CI}=(-1.33-1.36)]$.

There were no statistically significant difference between the occupation, nature of dietary intake of pregnant women and the serum levels of trace elements. $(\mathrm{F}=0.966 ; \mathrm{P}=0.415)$ and $(\mathrm{F}=0.485 ; \mathrm{P}=0.618)$ respectively.

Magnesium nutritional status can be influenced by a number of factors, but the easiest to correct is magnesium intake. In addition, dietary factors can modulate the absorption of the amount of magnesium ingested (Zola et al, 2009). In our survey, we found no statistically significant difference between the nature of dietary intake of pregnant women in Ika community and the mean serum level of magnesium. $(\mathrm{F}=0.485 ; \mathrm{p}=0.618)$.

Published data on maternal blood concentrations of manganese during pregnancy indicate higher concentrations of $15-20 \mu \mathrm{g} / \mathrm{L}$ than the values observed in the blood of the general adult population of 4-15 $\mu \mathrm{g} / \mathrm{L}$ (Kopp et al, 2012). This was similar to 
our finding except for the $4 \%$ that fell below this range.

Contrary to general belief that manganese deficiency cannot arise in humans because the element is widely distributed in foodstuffs, it has been reported that most western diets, even best planned, tend to be deficient in this important trace mineral partly due to the current farming methods, particularly the excessive use of agrochemicals which is known to cause severe manganese deficiencies, both in the soil and in the crop it yields (Sillanpaa, 1982). It has also been documented that nutritional manganese deficiency in humans can easily arise due to its poor absorption rate, combined with modern food production which strips manganese from the foodstuffs, from the soil to the table. Manganese absorption is also greatly hindered by the presence of other trace minerals, particularly of iron, as these two metals compete for the same binding sites, manganese having far inferior affinity to the carrier protein than iron. This observation was particularly noteworthy, as during pregnancy most women are routinely prescribed iron supplementation which further reduces the body manganese status (William,1971). However, in our report, we observed a dose response relationship between the serum levels of manganese and increase in gestational age despite the fact that all the pregnant women were placed on routine haematinics

Table 4: Mean values of trace elements among pregnant women versus trimester.

Serum Mg (standard deviation) Serum Mn (standard deviation)

\begin{tabular}{lllll}
\hline Trimester & & & & \\
\cline { 1 - 4 } First & 13.09 & $(2.36)$ & 20.22 & $(5.04)$ \\
Second & 12.17 & $(1.93)$ & 24.01 & $(7.89)$ \\
Third & 11.62 & $(1.30)$ & 24.45 & $(8.02$ \\
\hline
\end{tabular}

Because of the similarity in chemistry between $\mathrm{Mn}$ and $\mathrm{Mg}$ and because they can replace each other in several biochemical systems (Stephannsson et al, 2000), it is possible that with a reduction in dietary $\mathrm{Mn}$, dietary $\mathrm{Mg}$ will be utilized to a greater extent by the body. This could explain why the serum level of magnesium was declining why that of manganese was apparently normal to high.

Conclusion: The importance of trace elements in pregnancy and the consequent deficiencies cannot be over emphasized. Our diets in recent times consist of more and more refined foods and this has been of serious concern to the modern man who does not receive enough of these trace elements in his food from the soil to the table. There is therefore need to boost maternal awareness of dangers associated with deficiency of essential trace elements during pregnancy and dietary supplements may be of use in combating this shortage.
Recommendations: Elemental interactions among trace elements such as manganese, copper, zinc, iron and magnesium does exist and this contributes to variations in the plasma levels of these trace elements thereby resulting in deficiency of one or two of such elements. Regrettably however, most supplemental programmes in developing countries such as Nigeria mainly focus on iron supplementation with no concern for other trace elements. In view of the above, we recommend;

Prenatal supplementation should be encouraged in women of reproductive age as is done many developed countries such as USA 2. Government policy change such as in agro farming leaching agents should be discouraged. 3. Health education to pregnant women in Ika community on the need to supplement their diet. 4. We encourage further study, such as soil analysis in the locality to be able to accurately predict the level. 5. Base-line nutritional status of this sort is helpful in guarding against mineral deficiency or overload in the course of management of antenatal and postnatal women hence this study can be replicated in different parts of the country to establish a base line in the locality.

\section{REFERENCES}

Adam B, Malatyaliogu E, Alvur M, Talu C(2001). Magnesium, Zinc and Iron Levels in Preeclampsia. J. Matern. Foetal Med. , 10: 246-250.

Akinloye O, Oyewale OJ Oguntibeju OO(2010) . Evaluation of Trace Elements in Pregnant Women with Pre-eclampsia, Afr. J. of Biotechnol. ,9 (32): 5196-5202.

Aydemir F, Cavdar AO, Soylemez F, Cengiz B (2003). Plasma Zinc Levels During Pregnancy and its Relationship to Maternal and Neonatal Characteristics: a Longitudinal Study. Biolog Trace Element Res. ,91:193-202.

Burtis CA, Ashwood ER, Bruns DE (2008). Tietz Fundamentals of Clinical Chemistry. 496-508. Celli AB(1965).Variaciones del Magnesio Serico en el Embarazo Prto y puerpio Normales. Rev. Obst. Gin. . 25:585-599.

Chandra DC(2008). Societal Factors and Pregnancy Outcome (editorial). Nepal J Obstet Gynaecol:13.

Cortés YE, Moses L (2007). Magnesium Disturbances in Critically Ill Patients. Compend. 29 (7): 420-427.

DeJorge FB, Delascio D, Barros de Ulhoa Cintra A, Antunes ML(1965). Magnesium Concentration in the Blood Serum of Normal Pregnant Women. Obst. Gynec ,25:253-254. 
Emokpae MA, Eseosa RO Enaruna N(2015). Serum Levels of Calcium, Copper, Magnesium and Zinc in Nigerian Pregnant Women and Correlation with Gestational Periods. J. of Dis. and Global Health. ,2 (2): 2454-1842.

Gittelsohn J, Thapa M, Landman LT (1997). Cultural Factors, Caloric Intake and Micronutrient Sufficiency in Rural Nepali Household. Soc. Sci. Med. 44:1739-1749.

Goldstein GW(1990). Lead Poisoning and Brain Cell Function. Environ. Health Perspective. , 89: 9194.

Hall DG(1957). Serum Magnesium in Pregnancy. Obst. Gynec., ,9:158-162.

Hofmeyr GT, Duley L, Atallah A(2007). Dietary Calcium Supplementation for Prevention of Preeclampsia and Related Poblems: a Systematic Review and Commentary. Br. J. Obstet. Gynaecol. ,114 (8): 933-43.

Institute of Medicine(2001) . Dietary Reference Intakes for vitamin $\mathrm{A}$, vitamin $\mathrm{K}$, Arsenic, Boron, Chromium, Copper, Iodine, Iron, Manganese, Molybdenum, Nickel, Silicon, Vanadium, and Zinc. Food and Nutrition Board. National Academy Press, Washington, D.C., USA, pp797 .

Keen CL, Uriu-Hare JY, Hawk SN, Jankowski MA, Daston GP, Kwik-Uribe CL, et al(1998). Effect of Copper Deficiency on Prenatal Development and Pregnancy Outcome. Am. J. Clin. Nutr. , 67: 1003S-1011S

Kenako JJ(1999) . Clin. Biochem of Animal $4^{\text {th }}$ Edition. Kenako, J. J. (editor). Academic press Inc. New York., Pp 932.

Kopp RS, Kumbartski M, Harth V, Bruning T Kafferlein HU(2012). Partition of Metals in the Maternal-Foetal Unit and Lead-Associated Decreases of Foetal Iron and Manganese: An Observational Biomonitoring Approach. ,Archives of Toxicol.. 86, 1571-1581.

Krebs OS, Briggs AP(1923). Blood Studies in Normal Pregnancy. Am. J. Obst. Gynec. ,,5:6772 .

Larson SC, Wolk A(2007). Magnesium Intake and Risk of Type 2 Diabetes Mellitus: A MetaAnalysis. Intern. Med., 262:208-214.
Mahran M, Hanna S(1968). Magnesium Level in the Serum of Pregnant Women and in the Amniotic Fluid. J. Egypt Med. Assoc. ,, 51:251-257.

Mangum KC, Hill SF, Wade BB, Richards DO, Minton SD, Franz KB (1985). Effect of Age, Parity and Magnesium Supplementation on Muscle Cramping During Pregnancy. J. Am. Coil. Nutr., 4: 375-376.

Mistry HD, Paula J, Williams PJ (2011). The Importance of Antioxidant Micronutrients in Pregnancy. Oxid. Med. Cell Longev., 841749.

Nicoloff G, Mutaftchiev K, Strashimirov D, Petrova C(2004). Serum Manganese in Children With Diabetes Mellitus Type 1. Diabetologia Croatica., 33: 47-51.

Physician's Note Books. Secrets of Blood Test Reference. Lab Test Reference Values. Chapter 4, http://physiciansnotebook.blogspot.com, 2005

Ramakrishman U(2002). Prevalence of Micronutrient Malnutrition Worldwide. Nutr. Rev. S46-S52.

Sillanpaa M (1982). Micronutrients and the Nutrient Status of the Soils: a Global Study. FAO Soils Bulletin, Rome. 48.

Smith D, Gwiazda R, Bowler R, Roels H, Park R, Taicher C, et al (2007). Biomarkers of $\mathrm{Mn}$ Exposure in Humans. Am. J. Ind. Med., 50(11): 801-811.

Stephannsson O, Dickman PW, Johanson A, Cnattingiuss S(2000). Maternal Haemoglobin Concentration during Pregnancy and Risk of Stillbirth. J. of Ameri. Med. Assoc.. 284(20):2611-2617.

Tatsuo K(2009) . On the 2008 Revisions to the WMA Declaration of Helsinki. JMAJ ,,52(5): 293-318.

Tuntiseranee $\mathrm{P}$, Olsen J, Chongsuvivatwong V, Limbutara S (1999). Socio-Economic and Work related Determinants of Pregnancy Outcome in Southern Thailand. J. Epidemiol Communiy Health., 53:624-29.

Williams DR(1971). The Metals of Life. In: The Solution Chemistry of Metal ions in Biological Systems. Van. Nostrand Reinhold Co., London, UK., Pp 150-154.

Zota AR, Ettinger AS, Bouchard M, Amarasiriwardena CJ, Schwartz J, Wright RO et al(2009). Maternal Blood Manganese Levels and Infant Birth Weight. Epidemiology. ,20, 367-373. 